\title{
Preoperative Optimization of Patients Undergoing Ambulatory Surgery
}

\author{
Robert Fong • Bobbie Jean Sweitzer
}

Published online: 25 September 2014

(C) Springer Science + Business Media New York 2014

\begin{abstract}
As the percentage of surgical procedures performed in the outpatient setting continues to increase, development of standardized guidelines, recommendations for the preoperative assessment, and optimization of ambulatory surgery patients has become an increasing area of focus. While ambulatory surgery encompasses low-risk procedures and is generally well tolerated, the patients considered for these procedures manifest increasingly complex profiles of comorbidity. Minimizing perioperative adverse events among ambulatory surgery patients while maintaining responsible stewardship of health care resources and preventing unnecessary delays demands a thoughtful and evidence-based approach to preoperative assessment and medical optimization of comorbid conditions. This review summarizes current thought with regard to preoperative testing as well as assessment and management of important comorbid conditions in the ambulatory surgical population. General goals and specific recommendations based upon available evidence and expert consensus statements are provided to guide the preoperative management of patients considered for ambulatory surgery.
\end{abstract}

Keywords Preoperative optimization - Ambulatory surgery - Preoperative assessment $\cdot$ Cardiac testing . Obstructive sleep apnea - Diabetes - Preoperative testing . Cataract surgery

\footnotetext{
R. Fong · B. J. Sweitzer $(\square)$

Anesthesia Perioperative Medicine Clinic, The University of Chicago Medicine, 5841 South Maryland Avenue, MC 4028, Office A202, Chicago, IL 60637, USA

e-mail: bsweitzer@dacc.uchicago.edu

R. Fong

e-mail: Rfong@dacc.uchicago.edu
}

\section{Introduction}

Due to advances in minimally invasive surgery and improvements in anesthetic techniques and safety, recent years have witnessed a dramatic rise in the number of patients undergoing ambulatory surgical procedures. In the United States, over 50 million procedures are performed annually on an outpatient basis. Much of this increase in outpatient surgery is accounted for by free-standing surgicenters; in the period between 1996 and 2006 there was a $300 \%$ increase in procedures at such facilities while procedural volume at hospital based ambulatory surgery facilities remained relatively stable [1]. As this trend continues, there is increasing pressure from anesthesia providers to develop more standardized guidelines for the preoperative assessment and medical optimization of patients scheduled for outpatient surgery. In response, an increasing number of reviews have been published summarizing current data and thought with regard to preoperative assessment and optimization in the setting of a number of common comorbidities, and the Society for Ambulatory Anesthesia (SAMBA) has issued consensus statements covering important issues ranging from preoperative selection of patients with obstructive sleep apnea (OSA) $[2 \cdot \bullet$ to perioperative glucose management of diabetic patients $[3 \cdot \bullet]$.

Ambulatory surgery typically involves low-risk procedures and serious adverse outcomes are infrequent. The relative safety of outpatient surgery was confirmed by a recent Danish multicenter study of over 57,000 ASA PS 2 and 3 patients that revealed a low rate of morbidity, hospital admission within 30 days $(1.2 \%)$, and all cause 30-day mortality (24 patients) [4 $\cdot$. Of note, this 30-day mortality was actually less than that measured for age- and gender-matched controls. Data such as these in conjunction 
with myriad studies that have demonstrated lack of benefit and increased costs associated with routine preoperative testing, particularly in ambulatory surgery populations [4•, 5], have engendered a paradigm shift within the last decade with regard to the goals of preoperative assessment. This shift, which has moved the field away from ordering standard panels of tests in the hopes of identifying any as yet undiscovered abnormalities and toward more thoughtful risk assessment and management of comorbidities is well summarized in a recent review: "The pre-anesthesia visit is useful for patient evaluation, not specifically testing, but for the synthesis of information, medical optimization, additional targeted testing if indicated, assessment of risk, and plan for perioperative management [6]."

This review will address areas of preoperative assessment and medical optimization of the ambulatory surgery patient that have been chosen because they are either central to risk assessment and management or affect a large proportion of patients. These include indications for noncardiac preoperative testing, perioperative evaluation and management of cardiac disease, OSA, diabetes, obesity, and the cataract surgery patient. Many of these areas have undergone significant evolutions in thinking, and the goal of the present discussion is to provide a succinct summary of the most current evidence-based thought in each area along with practical recommendations for the ambulatory anesthesia provider.

\section{Perioperative Evaluation and Management of Cardiac Disease}

The focus of preoperative cardiac evaluation has undergone a definitive shift in the last decade away from routine testing and prophylactic revascularization and toward risk stratification and modification with increasing emphasis on medical management as a foundational approach. The publication of the 2014 ACC/AHA guidelines codifies this approach and provides a stepwise algorithm for the perioperative cardiovascular evaluation and care of patients undergoing non-cardiac surgery (Fig. 1) [7••]. Typically, ambulatory surgery carries a low risk of perioperative cardiac complications (defined by a cardiac risk of $<1 \%$ ). Most patients anticipating ambulatory surgery require no further assessment or testing in the absence of active cardiac conditions. In fact, even for intermediate and high-risk procedures, additional testing ought only be considered if the patient is unable to achieve a functional capacity of at least four METS, is at perioperative risk, and if a positive test result will alter management. When compared to the previous 2007 iteration [8], the 2014 ACC/AHA guidelines incorporate a more quantitative estimation of risk by considering both patient and procedure-specific risk factors, but continue to recommend the eschewing of further testing for patients with low combined risk.

Figure 1 summarizes the 2014 ACC/AHA algorithm for preoperative cardiac assessment of coronary artery disease (CAD). For the ambulatory surgery, patients with stable disease undergoing a non-emergent procedure, the centerpiece of preoperative evaluation is the quantitative assessment of the risk of major adverse cardiac events (MACE) incorporating both patient and procedure-specific risk. To compute this combined risk, the guidelines recommend using one of two approaches. The first employs a risk calculator (http://www.surgicalriskcalculator.com) developed in 2011 by the American College of Surgeons National Surgical Quality Improvement program (NSQIP) [9••, 10] in which patient specific variables (age, ASA class, functional status, and preoperative serum creatinine) as well as the procedure category are inputted to yield an estimated risk probability for perioperative myocardial infarction or cardiac arrest (MICA). The second approach employs the revised cardiac risk index (RCRI) that identifies diabetes requiring insulin, creatinine $\geq 2 \mathrm{mg} / \mathrm{dL}$, cerebrovascular accident or transient ischemic attack (TIA), ischemic heart disease, and heart failure (HF) as risk factors in conjunction with an estimation of surgical risk [11]. Patients at low risk ( $<1 \%$ or $<2$ clinical risk factors) may proceed to surgery without further testing. Those at elevated risk are assessed for functional capacity. Those who cannot achieve four METs or in whom functional capacity cannot be assessed are considered for cardiac stress testing if it will impact perioperative decision making or care, a decision often made after consultation with all members of the perioperative care team. If testing is not deemed necessary after such deliberation and consultation, the patient is managed medically with aspirin, statin, and beta-blocker therapy. In comparison to the $2007 \mathrm{ACC} /$ AHA guidelines in which ambulatory surgery as a category was considered low risk and did not require clinical risk factor assessment or further testing for the stable patient, the application of the 2014 guidelines may yield a category of ambulatory surgery patients in whom further testing is considered, particularly as higher risk procedures are attempted on higher risk patients in the outpatient setting.

Unstable or severe angina, a recent MI (within 60 days), decompensated or new onset HF, high-grade AV block, symptomatic arrhythmias or bradycardia, and severe aortic or mitral stenosis constitute active cardiac conditions that warrant additional evaluation prior to non-emergent surgery. It is worth noting that while preoperative cardiac assessment has tended to focus on patients with coronary disease, patients with active HF, significant valvular disease, and atrial fibrillation have a significantly higher risk of postoperative death than the patients with CAD [12•]. Patients with clinical HF (symptoms or physical 
Fig. 1 Algorithm for preoperative assessment of coronary artery disease. Adapted from Fleisher et al. $[7 \bullet \bullet]$

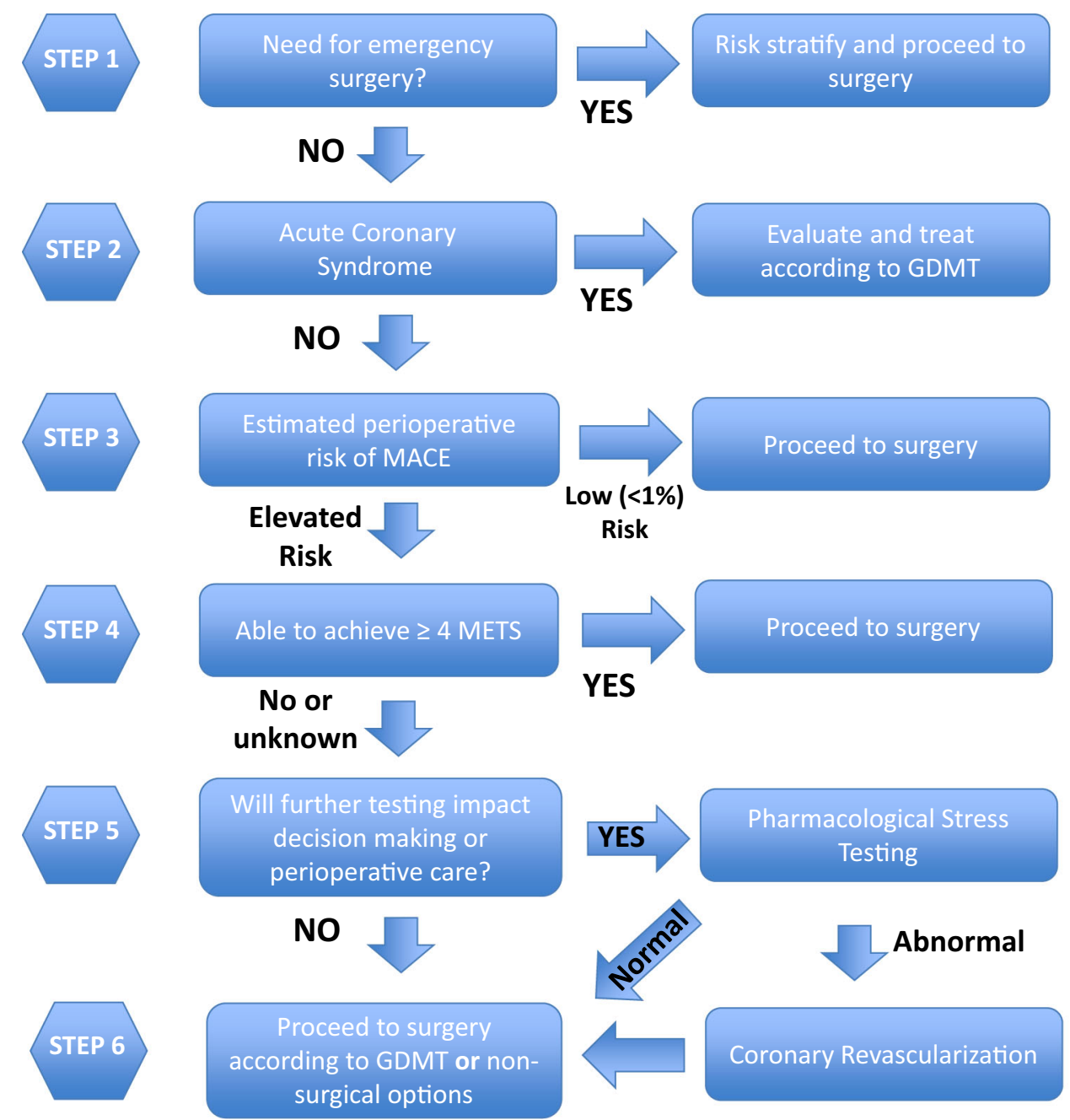

examination findings of peripheral edema, jugular venous distention, rales, third heart sound, or pulmonary edema on chest radiography) or a history of HF have a significant risk of perioperative complications [13]. The above underscore the importance of history taking and physical examination during the preoperative evaluation. The interview should explicitly address symptomatology related to these conditions including chest pain, dyspnea, syncope, and palpitations as well as any known cardiac history and interventions. The physical exam should be able to identify murmurs, irregularities of rate or rhythm, and stigmata of $\mathrm{HF}$ and volume overload.

Treatment and optimization of patients with $\mathrm{HF}$ in concert with HF specialists can improve perioperative outcomes [14]. Patients with suspected valvular abnormalities should undergo echocardiography to quantify the severity of stenosis or regurgitation, determine systolic function, and estimate right heart pressures. The risk of noncardiac surgery can be lowered by knowledge of the type and severity of valvular disease, appropriate anesthesia management, and an adequate perioperative monitoring (e.g., arterial pressure, pulmonary artery pressure, transesophageal echocardiography), as well as postoperative intensive care.

While there is no role for prophylactic percutaneous coronary intervention (PCI) prior to surgery except in the setting of unstable angina [15], patients may nevertheless present for surgery that have undergone recent PCI. Elective surgery is absolutely contraindicated within 30 days of bare metal stent [16, 17] placement and 12 months of drug-eluting stent placement. There may be special circumstances where it is acceptable to proceed with noncardiac surgery 6 months after DES placement when the procedure is of a more urgent nature. [18•, 19, 20]. Any interruption of dual antiplatelet prophylaxis during this period incurs a significant risk of stent re-thrombosis and undergoing surgery within these periods is associated with high morbidity and mortality [21, 22]. Antiplatelet agents should not be bridged 
with heparin or low molecular weight heparin (LMWH) in the setting of coronary stents as this strategy has been shown to actually increase the risk of stent re-thrombosis [23]. Aspirin should be continued for all patients with coronary stents of any duration for all procedures except those with the highest risk of bleeding [24, 25]. Due to their documented perioperative cardioprotective effects, patients taking betablockers or statins should be instructed to continue these medications through the day of surgery. Because urgent PCI is the best management for acute perioperative stent thrombosis, access to interventional cardiology should be considered in the selection criteria for higher risk patients seeking ambulatory surgery. In complex situations, consultation with the patient's cardiologist and the surgeon is recommended to formulate an optimal care plan and address issues such as timing of surgery, management of anticoagulation, and other potential risk reduction strategies.

Patients with artificial valves require careful consideration of the perioperative management of their anticoagulation as well as antibiotic endocarditis prophylaxis. Details of the anticoagulation requirements for patients with mechanical valves $[26,27]$ as well as other indications for endocarditis prophylaxis [28] are reviewed elsewhere, but in general these situations are best managed in collaboration with the patient's cardiologist.

History and physical examination may reveal the presence of a cardiovascular implantable electronic device (CIED) such as a pacemaker or defibrillator (ICD). The function of these devices can be altered by electromagnetic interference produced by equipment used in the operating room and lead to inappropriate delivery of shocks to the patient or inhibition of pacing. Intraoperative management of these devices is thoroughly reviewed elsewhere [29], but in general the anesthesiologist should ascertain the make and model of the device, the precise details of its mode and pacing function, and its response to magnet placement. The range and complexity of these devices is ever increasing, and as such consultation with a device expert is necessary to obtain all the needed information. The 2014 ACC/AHA guideline for evaluation and management for noncardiac surgery summarizes perioperative CIED management.

With regard to resting 12-lead electrocardiogram (ECG) the guidelines state that it "...is not useful for asymptomatic patients undergoing low-risk surgical procedures." For patients undergoing intermediate- or high-risk procedures, "preoperative resting 12-lead ECG is reasonable for patients with known coronary heart disease, significant arrhythmia, peripheral arterial disease, cerebrovascular disease, or other significant structural heart disease except for those undergoing low-risk surgery."

It is well-established and intuitive that patient-specific and procedure-related risk factors interact to predict overall perioperative cardiac risk. This argues for an individualized and thoughtful approach to the preoperative assessment and the perioperative management of patients with particular cardiovascular disease states and/or risk factors who intend to undergo particular procedures. In the ambulatory surgery setting, which embodies low-risk procedures, the preoperative evaluation tends to focus on the identification and optimization of patient-specific comorbidities and risks. This perioperative management is best executed in an interdisciplinary manner involving the patient's cardiologist and surgeon, particularly in complex or high-risk situations.

\section{Obstructive Sleep Apnea}

Obstructive sleep apnea is the most common form of sleepdisordered breathing that affects up to a quarter of the population and is increasing in incidence. It is estimated that upwards of $80 \%$ of individuals who are affected are unaware that they have it. Additionally, the incidence of OSA is greater in surgical populations [30]. OSA is associated with hypertension, arrhythmias, cor pulmonale, ischemic heart disease, diabetes, stroke, daytime sleepiness, depression, and reduced quality of life. Additionally, it is associated with significant perioperative morbidity and mortality [31, 32$]$. Perioperative concerns for the OSA patient include increased potential for difficult mask ventilation and intubation, oxygen desaturation and hypoxemia, exacerbation of cardiac comorbidities, delayed extubation, potential need for postprocedure re-intubation, prolonged recovery stay, hypoxic brain injury, and death. In light of the above, it is not surprising that considerable controversy has surrounded the question of whether patients with known or suspected OSA are suitable for ambulatory surgery.

In 2006, the ASA released guidelines relating to the identification and management of surgical patients with OSA [33]. These guidelines employ a 12-item screening questionnaire and propose a scoring system based on the severity of the OSA, anesthetic technique, the invasiveness of the surgical procedure, and the need for postoperative opioids to provide a semi-quantitative assessment of patient suitability for ambulatory surgery [34]. These guidelines go on to proscribe upper abdominal and airway procedures in the outpatient setting for patients with OSA.

Since the publication of the ASA guidelines, new developments and studies [35-37] have prompted SAMBA to issue a consensus statement in 2012 regarding the selection of patients with OSA for ambulatory surgery. Firstly, the screening tool of the ASA guidelines has been replaced by the more accessible and user-friendly STOPBang questionnaire, which has been validated in several different populations [38, 39]. This tool includes an 
assessment of snoring, tiredness, observed apnea, high blood pressure, Body-mass-index (BMI) $>35 \mathrm{~kg} / \mathrm{m}^{2}$, Age $>50$ years, neck circumference $>40 \mathrm{~cm}$, and male gender to arrive at a score ranging from 0 to 8 , in which the score is proportional to the probability of having OSA and possibly its severity. Recommendations for a cutoff score to consider the screening test "positive" range from 3 to 6 , with a higher cutoff conferring improved specificity and a score $\geq 5$ considered a "high" risk of having OSA [40 ${ }^{\bullet}$. Recent data suggests that male gender and BMI $>35 \mathrm{~kg} / \mathrm{m}^{2}$ may have more predictive power than neck circumference $>40 \mathrm{~cm}$ and age $\geq 50$ for those with STOP-Bang score $\geq 2$ $[41 \cdot]$.

Secondly, the systematic review of the literature by SAMBA considered a number of studies of OSA in ambulatory surgery populations published after $2006[3 \cdot \bullet]$. In contrast to previous studies of inpatient surgical populations that demonstrated serious cardiac and pulmonary complications in those with OSA, these studies reported no significant anesthesia-related adverse outcomes (delayed discharge, unanticipated admission, anoxic brain injury, or death) despite demonstrating a higher incidence of surrogate measures like postoperative hypoxemia, use of vasoactive drugs intra-operatively, and more attempts at laryngoscopy. Finally, as some of these studies included patients undergoing bariatric and laparoscopic procedures, upper abdominal procedures are no longer considered contraindications for ambulatory surgery in OSA patients.

Many of the patients in these studies used continuous positive airway pressure (CPAP) to manage their disease, and adverse perioperative outcomes seemed to be related to uncontrolled comorbid conditions and increased perioperative opioid use. Taken together, these observations suggest that in general patients with known or suspected OSA may be reasonable candidates for outpatient surgery if their co-morbidities (i.e., hypertension, HF, arrhythmias, cerebrovascular disease, metabolic syndrome) are well-controlled, and the use of opioids are minimized in favor of other classes of analgesics.

In early 2014, ASA released updated practice guidelines for the perioperative management of patients with OSA [42.•]. With respect to preoperative assessment, these guidelines recommend review of medical records, family and patient interview and physical exam to reveal known OSA or amass evidence suggesting the presence of OSA. Unlike the 2006 iteration, these guidelines no longer endorse the use of a particular screening tool, opting instead for a more comprehensive approach in which any historical or physical exam findings that have been reported in the literature to be associated with OSA are assessed. Beyond the STOP-Bang measures these include, for example, the presence of congenital or acquired conditions like down's syndrome, neuromuscular disease, or cerebral palsy; history of difficult intubation; and physical exam assessment of airway and nasopharyngeal characteristics, tonsil size, and tongue volume. The decision to obtain a sleep study and initiate treatment preoperatively in light of suspected OSA is left to the joint discretion of the surgeon and anesthesiologist. Provided in the guidelines is a scoring tool, not yet validated, to aid in risk stratification that includes consideration of the invasiveness of the planned procedure, the post-operative analgesic plan, and the severity of the sleep apnea. Patient selection for outpatient surgery is discussed: "Factors to be considered in determining whether outpatient care is appropriate include (1) sleep apnea status, (2) anatomical and physiologic abnormalities, (3) status of coexisting diseases, (4) nature of surgery, (5) type of anesthesia, (6) need for postoperative opioids, (7) patient age, (8) adequacy of post-discharge observation, and (9) capabilities of the outpatient facility. The availability of emergency difficult airway equipment, respiratory care equipment, radiology facilities, clinical laboratory facilities, and a transfer agreement with an inpatient facility should be considered in making this determination."

In light of available recommendations and guidelines, we recommend the following approach to the preoperative evaluation of OSA (Fig. 2). Patients with known OSA and optimized co-morbid conditions are considered appropriate for ambulatory surgery if they are able to use CPAP in the postoperative period. Patients with presumptive OSA based upon their STOP-Bang score or other suggestive history and exam findings are considered appropriate for ambulatory surgery if their co-morbid conditions are optimized and if an opioid sparing technique can be used to effectively manage postoperative pain. Consideration of other factors enumerated above from the 2014 ASA guidelines can assist in patient selection for ambulatory surgery in borderline risk situations. Additional recommendations to decrease the risk of adverse perioperative outcomes include favoring loco-regional techniques and sedation over general anesthesia, opting for a secure airway rather than deep sedation, and extubating patients fully awake in the semiupright position after ensuring complete reversal of neuromuscular blockade.

Implicit in these recommendations is the acknowledgement that while overnight polysomnography remains the gold standard for definitive diagnosis of sleep apnea, it is costly, time consuming, and of unproven benefit to perioperative outcome. Thus, those patients who are screened likely to have sleep apnea are treated as if they have the disease for purposes of patient selection for ambulatory surgery and perioperative management considerations. That said, a finding of severe OSA may impact patient selection for ambulatory surgery, and if a sleep study can be obtained to confirm the diagnosis of OSA without 
Fig. 2 Preoperative assessment of obstructive sleep apnea. Adapted from Joshi et al. [2••]

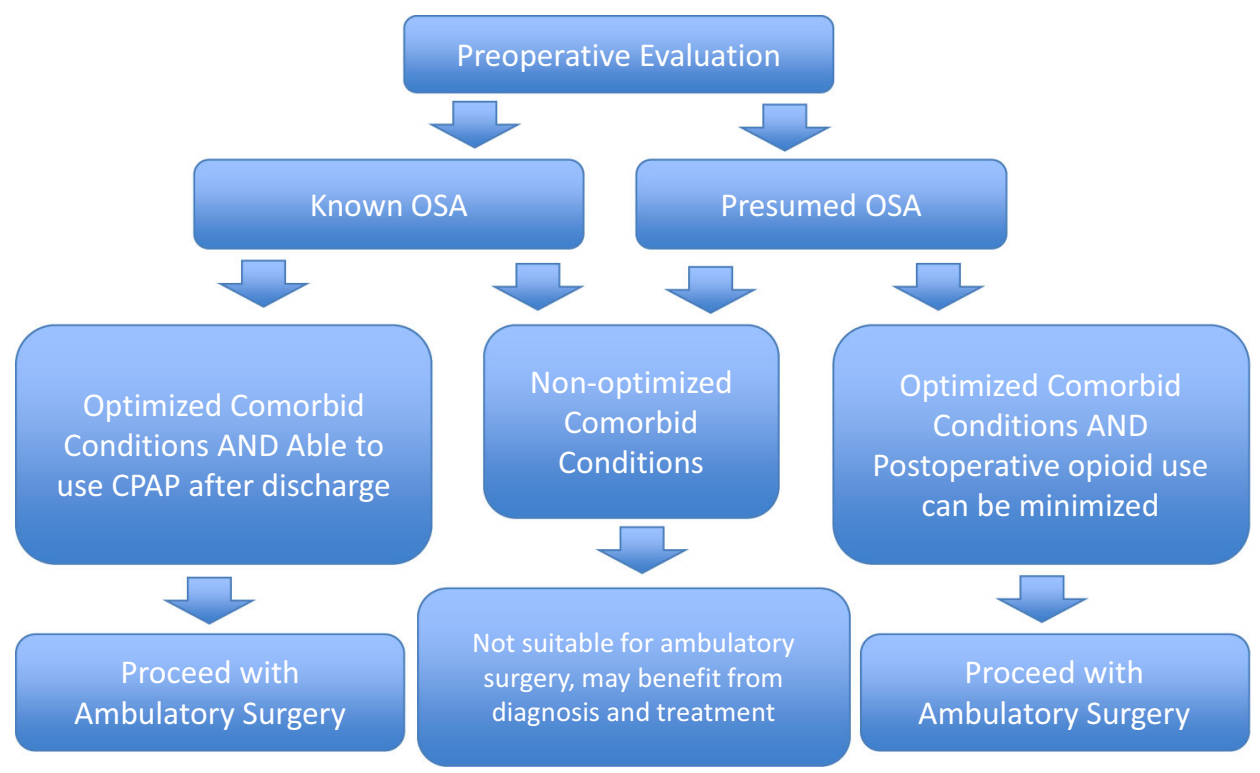

delaying surgery, there may be benefits related to obtaining a CPAP device titrated to appropriate settings that the patient is able to bring with her on the day of surgery for respiratory support in the post-operative period, as well as a long-term benefit of having initiated treatment of this chronic medical condition.

\section{Diabetes}

Currently, more than 26 million Americans have diabetes, and an estimated 79 million are pre-diabetic. As the incidence of diabetes continues to surge, an ever-increasing number of diabetic patients will present for ambulatory surgery. Diabetes is a chronic systemic disease with multiorgan system effects that can influence a patient's perioperative course including uncontrolled hyperglycemia, autonomic and peripheral neuropathy, gastroparesis, renal insufficiency, and increased risk of cardiovascular comorbidity. Sustained hyperglycemia engenders biochemical disturbances such as altered metabolism, ketoacidosis, and increased oxidative stress, hyperosmolarity, impaired leukocyte function, and coagulopathy. These cellular physiological effects translate to well-established perioperative morbidity within diabetic populations [43]. Accumulating evidence links poor glycemic control with adverse outcomes ranging from poor wound healing and increased surgical site infections [44] to increased mortality [45].

Consensus statements regarding glycemic management for hospitalized and critically ill patients as well as those undergoing major surgery have been advanced by the American Association of Clinical Endocrinologists (AACE) and the American Diabetes Association (ADA)
[46]. These recommendations reflect the current wisdom regarding the ongoing debate about the merits of tight glycemic control in these clinical settings. After initial enthusiasm for tight control strategies in the early to mid 2000s [47] more recent evidence suggests that these approaches may actually be detrimental due to increases in hypoglycemic episodes that may account for the increased mortality documented in some studies [48]. In response to demand from its members for standardized evidence-based recommendations regarding the perioperative management of diabetic ambulatory surgery patients, SAMBA released a consensus statement in 2010. While reaffirming the general goals of avoiding perioperative hypoglycemia with minimal perturbation to a patient's chronic glycemic management strategy, the accompanying literature review revealed scant evidence to support specific management strategies in the ambulatory surgery population. As such, recommendations were made by considering general approaches to diabetic management, pharmacological principles of anti-hyperglycemic agents, and insights from studies on inpatient populations.

The intraoperative management of blood glucose is well summarized in the SAMBA consensus statement as well as several recent reviews [49•,50,51•,52], and is not the focus of the present discussion, which will address instead the preoperative assessment and optimization of the diabetic ambulatory surgery candidate. The preoperative phase of care of the diabetic patients encompasses three main goals-1) an assessment of the burden of disease with regard to associated morbidity and organ involvement that can have anesthetic and perioperative implications, 2) an assessment and possible optimization of baseline glycemic control, and 3) perioperative management of a patient's 
oral hypoglycemic or insulin regimen. Once again, careful history and physical examination as well as clear communication with patients and members of the care team are central to the success of the preoperative endeavor in this area.

Surgery provokes a well-described neuroendocrine stress response that results in hyperglycemia and insulin resistance. While this response occurs in all patients, it can engender profoundly elevated and difficult to control perioperative blood glucose levels in the poorly managed diabetic patient (an insulin-deficient patient can manifest as much as a $45 \mathrm{mg} / \mathrm{dL}$ hourly increase in blood glucose level) [53]. Given the documented morbidity of poor perioperative glycemic control, it is incumbent on the members of the care team to have an accurate picture of the quality of the patient's baseline blood sugar control. This assessment should include the following information: a recent $\mathrm{HgA} 1 \mathrm{c}$ level, which evaluates average glycemic control over the last 3-4 months; an accurate log of doses of all oral hypoglycemic agents and insulins taken by the patient; the frequency and values of self-monitored blood sugar; the frequency and blood sugar threshold of hypoglycemic episodes and associated manifestations and hospitalizations. To date, there is insufficient evidence to establish a specific HgA1c cutoff to allow a patient to proceed with ambulatory surgery; although a review documenting an increased rate of adverse perioperative outcomes associated with $\mathrm{HgAlc}>7 \%$ (which incidentally corresponds to the ADA recommended target for outpatient diabetic management) may be suggestive [54]. In cases of elevated $\mathrm{HgA} 1 \mathrm{c}$ levels, a discussion with the surgeon regarding the potential for adverse outcomes in the context of the particular procedure planned and the patient's comorbidities is recommended. Manifestations of poor glycemic control including dehydration, ketoacidosis, or non-ketotic hyperosmolar states suggest the need for optimization of the patient's chronic management strategy prior to undergoing surgery. Consultation with the patient's primary care provider or endocrinologist is the cornerstone of these optimization efforts.

Efforts to prevent significant perioperative hyperglycemia while avoiding potentially dangerous hypoglycemia require careful management of patients' anti-diabetic medications. Recommendations for all oral anti-hyperglycemic agents and insulin formulations are provided in an excellent review [55•]. In general, oral diabetic medications are held on the day of surgery, long or intermediate acting insulin preparations are continued at a rate $50-100 \%$ of the normal daily dose depending on the baseline glycemic control and daily self measured blood sugar values, insulin pumps are programed to their lowest basal rate, and short acting meal time insulin preparations are discontinued due to the patient's NPO status. Evidence to support these recommendations is largely lacking, but the dominant underlying principle is the avoidance of hypoglycemia while attempting to maintain basal physiologic insulin levels perioperatively. Brittle diabetics with labile blood sugar present a challenge with respect to medication management, and in these cases consultation with the patient's endocrinologist is recommended.

\section{Obesity}

Obesity has reached epidemic proportions in the United States, affecting nearly $40 \%$ of the adult population [56]. BMI is the widely accepted quantitative surrogate for classifying the severity of disease; a BMI of $25-29.9 \mathrm{~kg} / \mathrm{m}^{2}$ is considered overweight, a BMI $>30 \mathrm{~kg} / \mathrm{m}^{2}$ obese, a BMI $>40 \mathrm{~kg} / \mathrm{m}^{2}$ morbidly obese, and a BMI $>50 \mathrm{~kg} / \mathrm{m}^{2}$ super-obese. Sheer prevalence guarantees that obesity will be encountered frequently in patients considered for ambulatory surgery in general, and the emergence of outpatient bariatric surgery in particular encompasses a category of patients for which obesity is the underlying operative diagnosis.

Obesity is a systemic disease that engenders a proinflammatory, pro-thrombotic state, and predisposes an individual to numerous co-morbid conditions including but not limited to diabetes, sleep apnea, and heart disease [57]. While evidence-based guidelines and recommendations have been advanced and here reviewed to guide preoperative assessment and management of these associated comorbidities, guidance in the literature regarding selection of obese patients appropriate for ambulatory surgery has been sparse. In response, SAMBA recently undertook the task of formulating recommendations regarding optimal selection of obese patients for ambulatory surgery [58••]. In the process of evaluating the literature, the authors found insufficient evidence upon which to base specific guidelines, but did provide an exhaustive review of available studies relating to perioperative outcomes in obese patients encompassing over 106,000 patients of which approximately $40 \%$ underwent bariatric surgery. A number of suggestive and useful insights emerged from the review. Some of the studies included in the review reported an increased incidence of hypoxemia, need for supplemental oxygen, need for airway maneuvers, laryngospasm, and bronchospasm among obese ambulatory surgery patients. In general, however, these did not translate to increases in serious adverse events or unanticipated readmission. Obese patients undergoing non-bariatric surgery have on average a lower BMI $\left(30 \mathrm{~kg} / \mathrm{m}^{2}\right)$ than those undergoing bariatric surgery $\left(>40 \mathrm{~kg} / \mathrm{m}^{2}\right)$, suggesting that current practice may be more conservative with respect to obese patient selection for outpatient surgery. The super-obese in general have 
a greater burden of co-morbid disease, and bariatric surgery in this population has been shown to be associated with worse perioperative outcome [59] and increased mortality $[60 \bullet$.

Accumulated evidence reinforces the notion that weight or BMI alone should not inform patient selection for ambulatory surgery. Bariatric surgery candidates routinely undergo rigorous preoperative evaluation, suggesting that careful optimization of co-morbid conditions may render obese patients suitable candidates for ambulatory surgery. Along these lines, morbidly obese patients may also be suitable for outpatient surgery after careful preoperative assessment, and in the absence of associated high-risk conditions including obesity-related hypoventilation syndrome, severe OSA, pulmonary hypertension, resistant hypertension, significant $\mathrm{CAD}$, or resistant cardiac failure. The super-obese, who are at higher risk for perioperative complications warrant more careful consideration before proceeding with ambulatory surgery, and in many cases may not be appropriate candidates. Additional factors that ought to be considered when making these patient selection decisions include invasiveness of the planned procedure, anesthetic technique, and venue characteristics. The effects of these additional factors on perioperative outcome in the obese ambulatory surgery population have not been rigorously studied, and represent an important area of future investigation.

\section{Non-cardiac Perioperative Testing}

Testing in the preoperative setting has value only to the extent that it refines risk assessment, changes perioperative management, improves outcome, or guides patient selection in the ambulatory setting. Ambulatory surgery encompasses low-risk procedures, in which patients with ASA PS 1 and 2 manifest a 20-fold lower mortality risk ( 0.06 and $0.08 \%$ respectively) than in all types of surgeries [61]. Additionally, a study of over 13,000 ambulatory surgery patients found that those who were ASA PS 3 and medically optimized were at similar risk for post-operative morbidity as ASA 1 and 2 patients [62]. Several decades of evidence in diverse surgical populations has convincingly demonstrated the lack of benefit and possible harm of indiscriminate routine testing. Only $2 \%$ of routine tests yield abnormal results [63] as compared to upwards of $30 \%$ of targeted testing [64]. Additionally, only an estimated $0.2-2 \%$ of abnormal tests actually result in changes in management $[65,66]$. Potential harm derives from morbidity associated with the follow-up of abnormal results, some of which may be false positives, as well as delays of surgery. While in many cases abnormal test results are simply ignored, such a practice has potential detrimental medico-legal implications. Economic costs of unnecessary testing are significant, as over $\$ 18$ billion is spent annually on preoperative testing [67].

In light of these observations, it is clear that the history and physical, rather than ordering of tests, constitute the foundation of effective preoperative evaluation of the ambulatory surgery patient. In this population, testing has minimal impact on perioperative outcome. Support for this concept is provided by a Canadian pilot study of over 1,000 patients randomized to indicate preoperative testing or no preoperative testing [68]. No difference in the rate of adverse perioperative events at 7 and 30 days was observed between the two groups. While the study excluded patients with significant cardiac and respiratory issues and was not adequately powered to detect differences in adverse events rare in the ambulatory surgery population, it nevertheless suggested that omitting testing did not engender significant harm.

Targeted testing may be appropriate in the preoperative evaluation of patients with known co-morbidities, although as pointed out in a recent comprehensive review, evidence in support of this remains sparse [4•]. Abnormal test results can often be anticipated by the history, such as electrolyte disturbances in patients with renal disease or on diuretics. Studies that have demonstrated correlations between abnormal test results and adverse perioperative events often suffer from the inherent problem of including patients with known disease process. For example, a correlation between preoperative hematocrit and perioperative transfusion can be plausibly explained by the existence in the study population of underlying processes that cause anemia. Nevertheless, testing is often required to assist in the management and optimization of comorbidities and can have value if results help in refining risk assessment even if they don't directly effect management. For example, measurement of renal function in patients with known renal disease will yield expected abnormal values, but as chronic renal failure with creatinine greater than $2 \mathrm{mg} / \mathrm{dL}$ predicts perioperative morbidity and mortality [69], the results of this measurement may inform risk stratification.

Table 1 presents situations in which common tests may be reasonably considered and of potential value in the preoperative assessment of the ambulatory surgery patient. Many of these situations are intuitive-measurement of hematocrit in the setting of anemia, liver function testing in the setting of cirrhosis, coagulation studies in setting of coagulopathy or chronic anticoagulation, etc. Some tests have no role in the assessment of the ambulatory surgery patient because the indications for obtaining them generally render the patient unfit for outpatient surgery. These include arterial blood gas measurement and chest X-ray. Pulmonary function testing has never been shown to improve perioperative outcome and as such is never indicated in the assessment of ambulatory surgery patients. In 
Table 1 Summary of tests and their indications for ambulatory surgery

\begin{tabular}{|c|c|c|}
\hline Test & Indicated & Exceptions \\
\hline $\begin{array}{l}\text { Complete blood } \\
\text { count }\end{array}$ & No & $\begin{array}{l}\text { Anemia } \\
\text { Anticipated blood loss }\end{array}$ \\
\hline $\begin{array}{l}\text { Coagulation } \\
\text { studies/platelets }\end{array}$ & No & $\begin{array}{l}\text { Personal/family history of bleeding } \\
\text { diathesis } \\
\text { Anticoagulants } \\
\text { Liver disease }\end{array}$ \\
\hline $\begin{array}{l}\text { Liver function } \\
\text { tests }\end{array}$ & No & $\begin{array}{l}\text { Risk assessment-cirrhosis } \\
\text { Acute history }\end{array}$ \\
\hline $\begin{array}{l}\text { Pulmonary } \\
\text { function testing }\end{array}$ & No & $\begin{array}{l}\text { Only as part of routine } \\
\text { management of asthma }\end{array}$ \\
\hline $\begin{array}{l}\text { Arterial blood } \\
\text { gases }\end{array}$ & No & - \\
\hline Urinalysis & No & Insertion of hardware \\
\hline Polysomnography & No & $\begin{array}{l}\text { Diagnosis and treatment for those } \\
\text { with non-optimized comorbid } \\
\text { conditions }\end{array}$ \\
\hline Chest X-ray & No & Evaluation of acute process \\
\hline Type and screen & - & $\begin{array}{l}\text { Anticipated blood loss }>500 \mathrm{cc} \\
\text { Rhogam }\end{array}$ \\
\hline Electrolytes & No & $\begin{array}{l}\text { Recent change in medications } \\
\text { affecting potassium/electrolytes }\end{array}$ \\
\hline Creatinine & No & Contrast dye study \\
\hline Glucose & No & Morning of surgery for diabetics \\
\hline
\end{tabular}

Adapted from Richman [61]

the setting of known lung disease preoperative evaluation relies upon an assessment of symptomatology, medication compliance, and physical exam.

\section{Cataract Surgery}

Cataracts constitute the most common surgical diagnosis among ambulatory surgery patients and cataract surgery ranks second to only GI endoscopy as the most frequent outpatient procedure, with over three million performed in the United States annually. Cataract surgery is characterized by low morbidity because it is most commonly performed under local anesthesia sometimes in conjunction with mild sedation, thus engendering minimal physiological stress. Nevertheless, patients undergoing cataract surgery tend to be elderly with numerous comorbidities. As such there has been interest in ascertaining whether preoperative testing could help guide patient selection.

The largest trial addressing the value of preoperative testing in cataract surgery patients was reported by Schein in 2000 [70]. Over 18,000 patients scheduled for cataract surgery were randomized to routine testing including ECG, $\mathrm{CBC}$, and basic metabolic panel versus no preoperative testing unless the patient developed a new condition that warranted testing even if the patient was not going to have surgery. No difference in adverse events or need for intervention on the day of surgery or 7 days after surgery was observed between the two groups. A $2 \%$ rate of cancelation of surgery was reported for both groups, implying that while testing did not seem to promote withholding of cataract surgery, it also did not affect patient selection. A recent Cochrane review that included this study and several more recent confirmed the lack of utility of preoperative testing prior to cataract surgery $[71 \bullet \cdot$. The larger number patients that have been studied allow for the detection of rare adverse events with sufficient statistical power. Thus, with respect to cataract surgery specifically it is possible to assert with confidence that preoperative testing is unwarranted.

A retrospective chart review of over 500 patients seen preoperatively prior to cataract surgery reported that a new medical issue was identified in $23 \%$ of patients while an unstable condition was identified in $22 \%$ of patients [72]. Despite this, surgery was delayed only $4 \%$ of the time. Attempts to develop simple screening tools to identify suitable candidates for cataract surgery under local anesthesia that obviate the need for formal preoperative assessment represent a significant cost saving opportunity. One example of such an attempt yielded promising results when used to screen 128 patients scheduled for cataract surgery [73]. The eight-item questionnaire addressed the ability to lay flat, to comprehend and communicate, the presence of psychiatric comorbidity, the presence and severity of gastroesophageal reflux, tremors, and cough. All of the patients successfully underwent cataract surgery without complication, with two patients for which the screening results recommended general anesthesia deemed fit for local anesthesia on the day of surgery. While there may be a role for preoperative assessment of cataract surgery patients when it is expected beforehand that they will require general anesthesia, routinely evaluating patients for their fitness to undergo general anesthesia is not a sound approach given the infrequency of unanticipated need for general anesthesia on the day of surgery.

\section{Conclusion}

As ambulatory surgery continues to grow and the range of procedures performed on an outpatient basis expands, there is increasing emphasis on the development of patient selection criteria as well as guidelines for preoperative evaluation and optimization of patients scheduled for these procedures. The low frequency of adverse events in ambulatory surgery populations makes it difficult to design 
studies with large enough sample sizes to detect differences between varied assessment and management strategies. Nevertheless, several themes emerge from a consideration of accumulated evidence:

(1) Ambulatory surgery encompasses low-risk procedures and is relatively safe and well tolerated.

(2) In general, routine testing does not seem to improve perioperative outcome and is associated with increased costs and morbidity.

(3) Targeted testing is useful to the extent that it assists in management and optimization of comorbidities or helps to refine risk stratification.

(4) History and physical exam constitute the foundation of effective preoperative management, and often provides more useful information than test results.

(5) Patients with complex comorbidities are most effectively managed collaboratively by communication with their surgeon and primary care or other specialist providers.

(6) In the ambulatory surgery population, low-risk patients without active or unstable cardiac conditions can proceed to surgery without further cardiac assessment.

(7) Medical therapy rather than procedural intervention is the cornerstone of preoperative management of the ambulatory surgery patient with stable cardiac disease.

(8) Patients with OSA can be appropriate candidates for ambulatory surgery if their comorbidities are wellcontrolled and they are able to use CPAP postoperatively.

(9) The STOP-Bang questionnaire is an effective tool to identify those who are likely to have OSA, and these patients may be appropriate for ambulatory surgery with an opioid sparing post-operative analgesic plan.

(10) Assessment and optimization of chronic blood sugar control and careful management of anti-diabetic medications are the primary goals in the preoperative management of the diabetic patient.

(11) While obese and morbidly obese patients may be appropriate for ambulatory surgery, if their attendant co-morbidities are optimized, super-obese patients may be at higher risk for perioperative complications.

(12) Preoperative assessment and testing is not generally indicated for patients undergoing cataract surgery.

Future multicenter studies in large populations to assess the impact of specific preoperative interventions on perioperative outcome will aid in further refining and standardizing the process of optimizing patients for ambulatory surgery.

\section{Compliance with Ethics Guidelines}

Conflict of Interest Robert Fong and Bobbie Jean Sweitzer declare that they have no conflict of interest.

Human and Animal Rights and Informed Consent This article does not contain any studies with human or animal subjects performed by any of the authors.

\section{References}

Papers of particular interest, published recently, have been highlighted as:

- Of importance

•- Of major importance

1. Cullen KA, Hall MJ, Golosinskiy A. Ambulatory surgery in the United States, 2006. Natl Health Stat Rep. 2009;11:1-25.

2. • Joshi GP, Ankichetty SP, Gan TJ, Chung F. Society for Ambulatory Anesthesia consensus statement on preoperative selection of adult patients with obstructive sleep apnea scheduled for ambulatory surgery. Anesth Analg. 2012;115(5):1060-8. doi:10.1213/ANE.0b013e318269cfd7. The STOP-Bang screening tool is central to the identification of ambulatory surgical candidates at risk for having OSA. Those with known or suspected OSA may be candidates for amblatory surgery if their comorbid conditions are well managed. Perioperative management strategies to minimize risk in the setting of known or suspected OSA are discussed.

3. • Joshi GP, Chung F, Vann MA, Ahmad S, Gan TJ, Goulson DT, et al. Society for Ambulatory Anesthesia consensus statement on perioperative blood glucose management in diabetic patients undergoing ambulatory surgery. Anesth Analg. 2010;111(6):1378-87. doi:10.1213/ANE.0b013e3181f9c288. Guidelines for the perioperative management of the diabetic ambulatory surgery patient formulated based on the best evidence available.

4. - Johansson T, Fritsch G, Flamm M, Hansbauer B, Bachofner N, Mann E et al. Effectiveness of non-cardiac preoperative testing in non-cardiac elective surgery: a systematic review. $\mathrm{Br} \mathrm{J}$ Anaesth. 2013;110(6):926-39. doi:10.1093/bja/aet071. Reviewing 101 studies, the authors find no evidence to recommend routine testing of healthy patients undergoing non-cardiac elective surgery, and limited evidence supporting targetted testing.

5. Benarroch-Gampel J, Sheffield KM, Duncan CB, Brown KM, Han Y, Townsend CM, et al. Preoperative laboratory testing in patients undergoing elective, low-risk ambulatory surgery. Ann Surg. 2012;256(3):518-28. doi:10.1097/SLA.0b013e31 $8265 \mathrm{bcdb}$.

6. Hofer J, Chung E, Sweitzer BJ. Preanesthesia evaluation for ambulatory surgery: do we make a difference? Curr Opin Anaesthesiol. 2013;26(6):669-76. doi:10.1097/ACO.00000000000 00006.

7. • Fleisher LA, Fleischmann KE, Auerbach AD, Barnason SA, Beckman JA, Bozkurt B, et al. 2014 ACC/AHA Guideline on perioperative cardiovascular evaluation and management of patients undergoing noncardiac surgery: executive summary: a report of the American College of Cardiology/American Heart Association task Force on Practice Guidelines. Circulation. 2014. doi:10.1161/CIR.0000000000000105. The most recent iteration of the ACC/AHA guidelines for the perioperative cardiac 
evaluation and management of patients undergoing noncardiac surgery and an exhaustive literature review.

8. Fleisher LA, Beckman JA, Brown KA, Calkins H, Chaikof E, Fleischmann KE, et al. ACC/AHA 2007 Guidelines on Perioperative Cardiovascular Evaluation and Care for Noncardiac Surgery: executive Summary: a report of the American College of Cardiology/American Heart Association Task Force on Practice Guidelines (Writing Committee to Revise the 2002 Guidelines on Perioperative Cardiovascular Evaluation for Noncardiac Surgery): developed in collaboration with the American Society of Echocardiography, American Society of Nuclear Cardiology, Heart Rhythm Society, Society of Cardiovascular Anesthesiologists, Society for Cardiovascular Angiography and Interventions, Society for Vascular Medicine and Biology, and Society for Vascular Surgery. Circulation. 2007;116(17):1971-96. doi:10. 1161/CIRCULATIONAHA.107.185700.

9. • Bilimoria KY, Liu Y, Paruch JL, Zhou L, Kmiecik TE, Ko CY, et al. Development and evaluation of the universal ACS NSQIP surgical risk calculator: a decision aid and informed consent tool for patients and surgeons. J Am Coll Surg. 2013;217(5):833-42.e1-3. doi:10.1016/j.jamcollsurg.2013.07.385. Describes the development of a surgical risk calculator based on multi-institutional data that incorporates patient and procedure specific factors to arrive at a combined perioperative risk estimate.

10. Cohen ME, Ko CY, Bilimoria KY, Zhou L, Huffman K, Wang X, et al. Optimizing ACS NSQIP modeling for evaluation of surgical quality and risk: patient risk adjustment, procedure mix adjustment, shrinkage adjustment, and surgical focus. J Am Coll Surg. 2013;217(2):336-346.e1. doi:10.1016/j.jamcollsurg.2013.02.027.

11. Lee TH, Marcantonio ER, Mangione CM, Thomas EJ, Polanczyk CA, Cook EF, et al. Derivation and prospective validation of a simple index for prediction of cardiac risk of major noncardiac surgery. Circulation. 1999;100(10):1043-9.

12. • van Diepen S, Bakal JA, McAlister FA, Ezekowitz JA. Mortality and readmission of patients with heart failure, atrial fibrillation, or coronary artery disease undergoing noncardiac surgery: an analysis of 38047 patients. Circulation. 2011;124(3):289-96. doi:10.1161/ CIRCULATIONAHA.110.011130. Despite the emphasis on coronary artery disease in preoperative cardiac assessment guidelines, this study reveals a higher perioperative mortality risk for patients with non-ischemic heart failure and atrial fibrillation.

13. Detsky AS, Abrams HB, McLaughlin JR, Drucker DJ, Sasson Z, Johnston N, et al. Predicting cardiac complications in patients undergoing non-cardiac surgery. J Gen Intern Med. 1986;1(4):211-9.

14. Xu-Cai YO, Brotman DJ, Phillips CO, Michota FA, Tang WH, Whinney CM, et al. Outcomes of patients with stable heart failure undergoing elective noncardiac surgery. Mayo Clin Proc. 2008;83(3):280-8. doi:10.4065/83.3.280.

15. McFalls EO, Ward HB, Moritz TE, Goldman S, Krupski WC, Littooy $\mathrm{F}$, et al. Coronary-artery revascularization before elective major vascular surgery. N Engl J Med. 2004;351(27):2795-804. doi:10.1056/NEJMoa041905.

16. Nuttall GA, Brown MJ, Stombaugh JW, Michon PB, Hathaway $\mathrm{MF}$, Lindeen $\mathrm{KC}$, et al. Time and cardiac risk of surgery after baremetal stent percutaneous coronary intervention. Anesthesiology. 2008;109(4):588-95. doi:10.1097/ALN.0b013e318186ddf8.

17. van Kuijk JP, Flu WJ, Schouten O, Hoeks SE, Schenkeveld L, de Jaegere PP, et al. Timing of noncardiac surgery after coronary artery stenting with bare metal or drug-eluting stents. Am J Cardiol. 2009;104(9):1229-34. doi:10.1016/j.amjcard.2009.06.038.

18. - Wijeysundera DN, Wijeysundera HC, Yun L, Wąsowicz M, Beattie WS, Velianou JL, et al. Risk of elective major noncardiac surgery after coronary stent insertion: a population-based study. Circulation. 2012;126(11):1355-62. doi:10.1161/ CIRCULATIONAHA.112.102715. A cohort study of over 8000 patients demonstrating that the risk of MACE approaches that of intermediate-risk non-revascularized patients after 180 days in those receiving drug-eluting stents.

19. Berger PB, Kleiman NS, Pencina MJ, Hsieh WH, Steinhubl SR, Jeremias A, et al. Frequency of major noncardiac surgery and subsequent adverse events in the year after drug-eluting stent placement results from the EVENT (evaluation of drug-eluting stents and ischemic events) registry. J Am Coll Cardiol Cardiovasc Interv. 2010;3(9):920-7. doi:10.1016/j.jcin.2010.03.021.

20. Hawn MT, Graham LA, Richman JS, Itani KM, Henderson WG, Maddox TM. Risk of major adverse cardiac events following noncardiac surgery in patients with coronary stents. J Am Med Assoc. 2013;310(14):1462-72. doi:10.1001/jama.2013.278787.

21. Iakovou I, Schmidt T, Bonizzoni E, Ge L, Sangiorgi GM, Stankovic $\mathrm{G}$, et al. Incidence, predictors, and outcome of thrombosis after successful implantation of drug-eluting stents. J Am Med Assoc. 2005;293(17):2126-30. doi:10.1001/jama.293.17.2126.

22. van Werkum JW, Heestermans AA, Zomer AC, Kelder JC, Suttorp MJ, Rensing BJ, et al. Predictors of coronary stent thrombosis: the Dutch stent thrombosis registry. J Am Coll Cardiol. 2009;53(16):1399-409. doi:10.1016/j.jacc.2008.12.055.

23. Webster SE, Payne DA, Jones CI, Hayes PD, Bell PR, Goodall $\mathrm{AH}$, et al. Anti-platelet effect of aspirin is substantially reduced after administration of heparin during carotid endarterectomy. J Vasc Surg. 2004;40(3):463-8. doi:10.1016/j.jvs.2004.06.022.

24. Burger W, Chemnitius JM, Kneissl GD, Rücker G. Low-dose aspirin for secondary cardiovascular prevention-cardiovascular risks after its perioperative withdrawal versus bleeding risks with its continuation: review and meta-analysis. J Intern Med. 2005;257(5):399-414. doi:10.1111/j.1365-2796.2005.01477.x.

25. Devereaux PJ, Mrkobrada M, Sessler DI, Leslie K, Alonso-Coello P, Kurz A, et al. Aspirin in patients undergoing noncardiac surgery. N Engl J Med. 2014;370(16):1494-503. doi:10.1056/ NEJMoa1401105.

26. Douketis JD, Berger PB, Dunn AS, Jaffer AK, Spyropoulos AC, Becker RC, et al. The perioperative management of antithrombotic therapy: American College of Chest Physicians EvidenceBased Clinical Practice Guidelines (8th Edition). Chest. 2008;133(6 Suppl):299S-339S. doi:10.1378/chest.08-0675.

27. Spyropoulos AC, Douketis JD. Guidelines for antithrombotic therapy: periprocedural management of antithrombotic therapy and use of bridging anticoagulation. Int Angiol. 2008;27(4):333-43.

28. Wilson W, Taubert KA, Gewitz M, Lockhart PB, Baddour LM, Levison M, et al. Prevention of infective endocarditis: guidelines from the American Heart Association: a guideline from the American Heart Association Rheumatic Fever, Endocarditis, and Kawasaki Disease Committee, Council on Cardiovascular Disease in the Young, and the Council on Clinical Cardiology, Council on Cardiovascular Surgery and Anesthesia, and the Quality of Care and Outcomes Research Interdisciplinary Working Group. Circulation. 2007;116(15):1736-54. doi:10. 1161/CIRCULATIONAHA.106.183095.

29. Stone ME, Apinis A. Current perioperative management of the patient with a cardiac rhythm management device. Semin Cardiothorac Vasc Anesthesiol. 2009;13(1):31-43. doi:10.1177/ 1089253209332211.

30. Singh M, Liao P, Kobah S, Wijeysundera DN, Shapiro C, Chung F. Proportion of surgical patients with undiagnosed obstructive sleep apnoea. Br J Anaesth. 2013;110(4):629-36. doi:10.1093/ bja/aes465.

31. - Kaw R, Chung F, Pasupuleti V, Mehta J, Gay PC, Hernandez AV. Meta-analysis of the association between obstructive sleep apnoea and postoperative outcome. $\mathrm{Br} \mathrm{J}$ Anaesth. 2012;109(6):897-906. doi:10.1093/bja/aes308. A meta-analysis of 13 studies demonstrating an increased incidence of postoperative oxygen desaturation, repiratory failure, cardiac events and ICU admission in patients with OSA. 
32. Memtsoudis S, Liu SS, Ma Y, Chiu YL, Walz JM, Gaber-Baylis LK, et al. Perioperative pulmonary outcomes in patients with sleep apnea after noncardiac surgery. Anesth Analg. 2011;112(1):113-21. doi:10.1213/ANE.0b013e3182009abf.

33. Gross JB, Bachenberg KL, Benumof JL, Caplan RA, Connis RT, Coté CJ, et al. Practice guidelines for the perioperative management of patients with obstructive sleep apnea: a report by the American Society of Anesthesiologists Task Force on Perioperative Management of patients with obstructive sleep apnea. Anesthesiology. 2006;104(5):1081-93 quiz 117-8.

34. Chung F, Yegneswaran B, Liao P, Chung SA, Vairavanathan S, Islam S, et al. Validation of the Berlin questionnaire and American Society of Anesthesiologists checklist as screening tools for obstructive sleep apnea in surgical patients. Anesthesiology. 2008;108(5):822-30. doi:10.1097/ALN.0b013e31816d91b5.

35. Liu SS, Chisholm MF, Ngeow J, John RS, Shaw P, Ma Y, et al. Postoperative hypoxemia in orthopedic patients with obstructive sleep apnea. Hosp Spec Surg J. 2011;7(1):2-8. doi:10.1007/ s11420-010-9165-0.

36. Kurrek MM, Cobourn C, Wojtasik Z, Kiss A, Dain SL. Morbidity in patients with or at high risk for obstructive sleep apnea after ambulatory laparoscopic gastric banding. Obes Surg. 2011;21(10):1494-8. doi:10.1007/s11695-011-0381-6.

37. Baugh R, Burke B, Fink B, Garcia R, Kominsky A, Yaremchuk K. Safety of outpatient surgery for obstructive sleep apnea. Otolaryngol Head Neck Surg. 2013;148(5):867-72. doi:10.1177/ 0194599813479776.

38. Chung F, Yegneswaran B, Liao P, Chung SA, Vairavanathan S, Islam S, et al. Stop questionnaire: a tool to screen patients for obstructive sleep apnea. Anesthesiology. 2008;108(5):812-21. doi:10.1097/ALN.0b013e31816d83e4.

39. Farney RJ, Walker BS, Farney RM, Snow GL, Walker JM. The STOP-Bang equivalent model and prediction of severity of obstructive sleep apnea: relation to polysomnographic measurements of the apnea/hypopnea index. J Clin Sleep Med. 2011;7(5):459-65B. doi:10.5664/JCSM.1306.

40. • Chung F, Subramanyam R, Liao P, Sasaki E, Shapiro C, Sun Y. High STOP-Bang score indicates a high probability of obstructive sleep apnoea. Br J Anaesth. 2012;108(5):768-75. doi:10.1093/ $\mathrm{bja} / \mathrm{aes} 022$. A study of 746 surgical patients showing that a STOP-Bang score of 5-8 predicted the preence of moderate to severe OSA.

41. Chung F, Yang Y, Brown R, Liao P. Alternative scoring models of STOP-Bang questionnaire improve specificity to detect undiagnosed obstructive sleep apnea. J Clin Sleep Med. 2014;10(9):951-8 A study of 516 surgical patients demonstrating the greater predictive power of male gender and $B M I \geq 35 \mathrm{~kg} /$ $\mathrm{m}^{2}$ compared to age $\geq 50$ and neck circumference $>40 \mathrm{~cm}$ in identifying patients with OSA.

42. • Practice guidelines for the perioperative management of patients with obstructive sleep apnea: an updated report by the American Society of Anesthesiologists Task Force on perioperative management of patients with obstructive sleep apnea. Anesthesiology. 2014;120(2):268-86. doi:10.1097/ALN. 0000000000000053. The most recent iteration of guidelines from the ASA regarding perioperative management of patients with OSA and a review of recent literature.

43. Akhtar S, Barash PG, Inzucchi SE. Scientific principles and clinical implications of perioperative glucose regulation and control. Anesth Analg. 2010;110(2):478-97. doi:10.1213/ANE. 0b013e3181c6be63.

44. Richards JE, Kauffmann RM, Zuckerman SL, Obremskey WT, May AK. Relationship of hyperglycemia and surgical-site infection in orthopaedic surgery. J Bone Joint Surg Am. 2012;94(13):1181-6. doi:10.2106/JBJS.K.00193.
45. Noordzij PG, Boersma E, Schreiner F, Kertai MD, Feringa HH, Dunkelgrun M, et al. Increased preoperative glucose levels are associated with perioperative mortality in patients undergoing noncardiac, nonvascular surgery. Eur J Endocrinol. 2007;156(1):137-42. doi:10. 1530/eje.1.02321.

46. Moghissi ES, Korytkowski MT, DiNardo M, Einhorn D, Hellman R, Hirsch IB, et al. American Association of Clinical Endocrinologists and American Diabetes Association consensus statement on inpatient glycemic control. Diabetes Care. 2009;32(6):1119-31. doi:10.2337/dc09-9029.

47. van den Berghe G, Wouters P, Weekers F, Verwaest C, Bruyninckx F, Schetz M, et al. Intensive insulin therapy in critically ill patients. N Engl J Med. 2001;345(19):1359-67. doi:10.1056/ NEJMoa011300.

48. Griesdale DE, de Souza RJ, van Dam RM, Heyland DK, Cook DJ, Malhotra A, et al. Intensive insulin therapy and mortality among critically ill patients: a meta-analysis including nice-sugar study data. Can Med Assoc J. 2009;180(8):821-7. doi:10.1503/ cmaj.090206.

49. • Sebranek JJ, Lugli AK, Coursin DB. Glycaemic control in the perioperative period. Br J Anaesth. 2013;111(Suppl 1):i18-34. doi:10.1093/bja/aet381. A review of recent studies providing recommendations for the preoperative assessment and perioperative management of dysglycemic patients.

50. Vann MA. Perioperative management of ambulatory surgical patients with diabetes mellitus. Curr Opin Anaesthesiol. 2009;22(6):718-24. doi:10.1097/ACO.0b013e3283310f51.

51. • Buchleitner AM, Martínez-Alonso M, Hernández M, Solà I, Mauricio D. Perioperative glycaemic control for diabetic patients undergoing surgery. Cochrane Database Syst Rev. 2012;9:CD007315. doi:10.1002/14651858.CD007315.pub2. A Cochrane review demonstrating no benefit to intensive perioperative glycemic control with an increased risk of hypoglycemia.

52. Dell'Aquila AM, Ellger B. Perioperative glycemic control: what is worth the effort? Curr Opin Anaesthesiol. 2013;26(4):438-43. doi:10.1097/ACO.0b013e328362d16a.

53. Moitra VK, Greenberg J, Arunajadai S, Sweitzer B. The relationship between glycosylated hemoglobin and perioperative glucose control in patients with diabetes. Can J Anaesth. 2010;57(4):322-9. doi:10.1007/s12630-010-9266-8.

54. Dronge AS, Perkal MF, Kancir S, Concato J, Aslan M, Rosenthal RA. Long-term glycemic control and postoperative infectious complications. Arch Surg. 2006;141(4):375-80. doi:10.1001/ archsurg.141.4.375 discussion 80 .

55. - Vann MA. Management of diabetes medications for patients undergoing ambulatory surgery. Anesthesiol clin. 2014;32(2):329-39. doi:10.1016/j.anclin.2014.02.008. A comprehensive and succint review of the recommended preoperative management of oral anti-hyperglycemic agents and insulin formulations.

56. Ogden CL, Carroll MD, Kit BK, Flegal KM. Prevalence of obesity among adults: United States, 2011-2012. NCHS Data Br. 2013;131:1-8.

57. Cullen A, Ferguson A. Perioperative management of the severely obese patient: a selective pathophysiological review. Can J Anaesth. 2012;59(10):974-96. doi:10.1007/s12630-012-9760-2.

58. •• Joshi GP, Ahmad S, Riad W, Eckert S, Chung F. Selection of obese patients undergoing ambulatory surgery: a systematic review of the literature. Anesth Analg. 2013;117(5):1082-91. doi:10.1213/ANE.0b013e3182a823f4. A comprehensive literature review of studies relating obesity to perioperative outcomes that provides guidance with regard to selection of obese patients for ambulatory surgery.

59. Flum DR, Belle SH, King WC, Wahed AS, Berk P, Chapman W, et al. Perioperative safety in the longitudinal assessment of 
bariatric surgery. N Engl J Med. 2009;361(5):445-54. doi:10. 1056/NEJMoa0901836.

60. - Kakarla VR, Nandipati K, Lalla M, Castro A, Merola S. Are laparoscopic bariatric procedures safe in superobese (BMI $\geq 50 \mathrm{~kg} / \mathrm{m} 2$ ) patients? An NSQIP data analysis. Surg Obes Rela Dis. 2011;7(4):452-8. doi:10.1016/j.soard.2010.10.009. An analysis of NSQIP data for 29,323 laparoscopic bariatric procedures demonstrating an increase in perioperative complications and 30-day mortality among the superobese (BMI $\left.>50 \mathrm{~kg} / \mathrm{m}^{2}\right)$.

61. Richman DC. Ambulatory surgery: how much testing do we need? Anesthesiol Clin. 2010;28(2):185-97. doi:10.1016/j.anclin. 2010.03.001.

62. Natof HE. Pre-existing medical problems. Ambulatory surgery. IMJ Ill Med J. 1984;166(2):101-4.

63. Smetana GW, Macpherson DS. The case against routine preoperative laboratory testing. Med Clin North Am. 2003;87(1):7-40.

64. Charpak Y, Blery C, Chastang C, Ben Kemmoun R, Pham J, Brage $\mathrm{D}$, et al. Usefulness of selectively ordered preoperative tests. Med Care. 1988;26(2):95-104.

65. Kaplan EB, Sheiner LB, Boeckmann AJ, Roizen MF, Beal SL, Cohen $\mathrm{SN}$, et al. The usefulness of preoperative laboratory screening. J Am Med Assoc. 1985;253(24):3576-81.

66. Bryson GL, Wyand A, Bragg PR. Preoperative testing is inconsistent with published guidelines and rarely changes management. Can J Anaesth. 2006;53(3):236-41. doi:10.1007/BF03022208.

67. Roizen MF. More preoperative assessment by physicians and less by laboratory tests. N Engl J Med. 2000;342(3):204-5. doi:10. 1056/NEJM200001203420311.
68. Chung F, Yuan H, Yin L, Vairavanathan S, Wong DT. Elimination of preoperative testing in ambulatory surgery. Anesth Analg. 2009;108(2):467-75. doi:10.1213/ane.0b013e318176bc19.

69. Smetana GW, Lawrence VA, Cornell JE, et al. Preoperative pulmonary risk stratification for noncardiothoracic surgery: systematic review for the American College of Physicians. Ann Intern Med. 2006;144(8):581-95.

70. Schein OD, Katz J, Bass EB, Tielsch JM, Lubomski LH, Feldman MA, et al. The value of routine preoperative medical testing before cataract surgery. Study of Medical Testing for Cataract Surgery. N Engl J Med. 2000;342(3):168-75. doi:10.1056/ NEJM200001203420304.

71. • Keay L, Lindsley K, Tielsch J, Katz J, Schein O. Routine preoperative medical testing for cataract surgery. Cochrane Database Syst Rev. 2012;3:CD007293. doi:10.1002/14651858. CD007293.pub3. A Cochrane review demonstrating that routine preoperative testing does not improve the safety of cataract surgery even for older patients with mulitple comorbidities.

72. Phillips MB, Bendel RE, Crook JE, Diehl NN. Global health implications of preanesthesia medical examination for ophthalmic surgery. Anesthesiology. 2013;118(5):1038-45. doi:10.1097/ ALN.0b013e31828ea5b2.

73. MacPherson R. Structured assessment tool to evaluate patient suitability for cataract surgery under local anaesthesia. Br J Anaesth. 2004;93(4):521-4. doi:10.1093/bja/aeh243. 